mothers as revolutionary feminists or as traitors to the feminist cause. This is a simplification of debate and erases the more complex coverage - albeit occasional - that appears in both forums. More importantly, I find Thompson's underlying tenet of 'lesbian mother as oxymoron' troubling because it sets up lesbian and mother as mutually exclusive categories, which contradicts the lived experiences of many lesbian mothers and the differences among lesbian parent families. While Thompson states that she wants to redeploy lesbian mother as oxymoron, the rigidity of her focus tends to foreclose a thoroughness of exposition on the subject. Furthermore, the irony is that by structuring her hypothesis around this polemical presupposition she may actually valorize the antithetical status of lesbian mother and give credence to anti-lesbian rhetoric. Notwithstanding these reservations, Thompson's book does provide some interesting points of analysis and will be useful to scholars and activists who work and/or study in the area of lesbian parent families.

doi: 10.1057/palgrave.fr. 9400331

Jacqui Gabb

\title{
The intimate economies of Bangkok: tomboys, tycoons and Avon ladies in the global city
}

Ara Wilson; University of California Press, Berkeley, 2004, xvi $+272 p p .$, maps, illustrations, references, index, ISBN 05-2023-783-8, £32.50 (hbk); ISBN 05-2023-968-7, £8.50 (pbk)

Much has been written lately on the phenomenon of globalization and how best to study and theorize the multiple ways in which places, cultures and people interact with global economic and cultural practices and ideologies. Sadly, the debate has tended to descend into moralizing arguments that emphasize a distinctive break between local, traditional, authentic (real) cultures and the global abstract flow of Western-originating, capitalist and hegemonic modernity, forever foreign to anywhere but the 'West', and where the latter will sooner or later destroy the former.

Ara Wilson's The Intimate Economies of Bangkok is an overall excellently argued and ambitious exercise in how globalization can and must be studied: through detailed, long-term ethnographic research in local places, and keen participant observation of everyday practices in socio-cultural context. Wilson explores the dynamic and highly complex interaction between global market economy and Bangkok's 'intimate economies' - meaning everyday practices and beliefs related to people's sense of their social identities and relationships, especially in terms of gender, sexuality and kinship. The aim is to 'capture the deeply felt 
orientations and entrenched practices that make up what people consider to be their personal or private lives and their individual selves' (p. 11). Wilson overall succeeds in her ambition, and thus allows the reader to grasp some of the complex, multiple and highly contradictory ways in which global capitalism works locally, the relationships this interchange generates, how they mutually draw on, and ultimately change, each other over time.

The book is divided into five main chapters that each portray and analyse in detail (seemingly) different Bangkok markets: the department store and shop houses, the go-go bar and sex market catering to Western tourists, downtown shopping complexes, professional corporate marketing and the direct sales market. Each shows through highly readable descriptions that exude the author's keen understanding of the cultural geographies that inform them, how intimate aspects of local lives are inextricably intertwined with global capitalist practices and logics.

Take, for example, the young and highly educated professional marketing woman Kop in Chapter four, to my mind the best-argued section of the book. Wilson evokes Aihwa Ong's notion of the flexible citizen to describe the professional knowledge worker in multinational corporate marketing. Kop studied abroad in the US, and then returned to a Thai-founded yet transnationally operating ICT company in Bangkok. She capitalizes on her English language and Western culture knowledge base, herself being an avid consumer of 'foreign...symbolic technologies' ( $p .148$ ) and a keen participant in global culture (that involves singing along to Barry Manilow for example). In turn this informs a certain worldliness that utilizes local and global hierarchies of belonging and citizenship in cosmopolitan Bangkok. However, Kop's future life plans are inextricably interwoven with requirements of her natal family and social judgments, as she un-married and nearing thirty - is living at home with her family under strict scrutiny. Foremost on her mind are not Hollywood-style romance and typically modern ideals about love and sex, but rather marrying 'up' and thus securing crucial fidelity and family approval, as well as concerns about money and consuming power.

The concept of economy emerges a key theme of enquiry throughout the book. Wilson argues introductorily, and shows through the ethnographic portraits, that capitalist market logic seemingly excludes aspects of local Thai folk economies based in exchange systems where social relations are crucial, and which value women's presence as core participants and strategizers. However, the direct saleswomen who also operate market stalls in the bustling downtown Bangkok rely on highly personalized methods of approach and advertising techniques to distribute their Avon and Amway products. Modern capitalism has contributed strongly to cementing a traditionalized ideology of gender relations, such as normative femininity as non-economic and domestic, and a feminization of consumption aided by media and advertising strategies - all intimate 
components of global capitalist culture. Wilson's ethnographic portraits thus explore how ideologies and practices of both systems exist simultaneously and are inextricably linked with each other. The portraits tend to emphasize women as economic agents, for instance as workers in go-go bars, as corporate marketers or home sales business-women. Wilson explores how the women are strategizing and utilizing agentive positions that are informed by various other markers of identity such as ethnicity, class, level of education, gender and sexual roles. Dominant messages of modern heteronormative femininity, sexuality and romance in shopping mall layout, shop structures and advertising, for example, are strategically modified by tomboy women who accommodate these unintended appropriations of spaces and discourses for displaying and developing a female masculine subjectivity, engaging in homo-social relationship in public, albeit unnoticed, with other toms or with their dee (feminine) girlfriends.

The Intimate Economies of Bangkok is for these reasons an important and intriguing read. However, the complexity and diversity of the research theme, and its holistic approach to empirical analysis, makes the book sometimes uneven and seemingly oversimplifying in its analysis of diverse current practices and their specific histories. The book could perhaps have benefited from a closer focus on fewer arenas, rather than the five discussed in different chapters of less than 200 pages. Nevertheless, this remains an eloquently argued ethnography of global capitalism and cultures, of the interrelationship between local and global, rural and urban, diverse gender and sexual ideologies, and the intricate ways in which transformations are unfolding within contemporary Thai society.

doi: $10.1057 /$ palgrave.fr. 9400330

Elisabeth Lund Engebretsen 